\title{
Trajectories of radicalization and resilience in Nuruddin Farah's North of Dawn Vivian Gerrand
}

\section{Trajectories of radicalization and resilience in Nuruddin Farah's North of Dawn}

Situated within a body of writing that is preoccupied with engagement with terrorism, this article considers the ways in which Nuruddin Farah's novel, North of Dawn (2018), explores trajectories of radicalization and resilience to violent extremism. Written from an interdisciplinary cultural migration studies perspective, the article understands violent extremism as a complex networked phenomenon. It makes an original contribution by highlighting the role of belonging in trajectories of radicalization and resilience, bringing sociological studies of radicalized violence and resilience to such violence into dialogue with a cosmopolitan literary framework including the works of other diasporic Somali background European writers such as Cristina Ali Farah and Igiaba Scego. Keywords: radicalization to violent extremism, resilience, Nuruddin Farah, belonging, conviviality, fascism.

Set in contemporary Oslo, Nuruddin Farah's novel, North of Dawn (2018), explores the radicalization and resilience of Somalis living in Europe. Somalis have resettled in Norway since the mid-1980s, and now number approximately 40 000, including the children of Somali migrants (Tellander and Horst 142). In Oslo, where they are most concentrated, Somalis are now one of the biggest immigrant groups and have high levels of Norwegian citizenship acquisition (143). Narrated polyphonically, predominantly through the eyes of its male protagonists Mugdi and his step grandson Naciim, the novel tells the story of what happens when a Somali Norwegian family loses its son to involvement in terrorism, and explores associated questions of identity and belonging or lack thereof in the diaspora.

If the dynamic interaction of different cultures and languages has become an everyday reality for diasporic Somalis in the increasingly cosmopolitan societies in which they dwell globally, so have fear and resistance to such diversity, both within and outside of the diaspora. Indeed, the perceived existential threat posed by interaction with difference is a critical authorial concern in North of Dawn. Farah's valorization of humanist cosmopolitanism, and convivial democratic coexistence, challenges the fascist ideologies shared by neo-Nazi and jihadist extremists alike. His novel enables readers to understand the ways in which belonging is sought both in destructive trajectories of radicalization to violent extremism and in cosmopolitan inclusiveness that enables resilience to such violence.

As in Farah's earlier works, questions of gender and generation are central preoccupations, and inform tensions between family members and their responses to the traumas inherent in the characters' experiences of living in exile. Drawing on earlier work on representations of Somali belonging (Gerrand, "Representing Somali Resettlement in Italy: The Writing of Ubax Cristina Ali Farah and Igiaba Scego" and "Mending Mogadishu. Somali Belonging in the twenty-first century") and on recent research with the families of young people who joined violent extremist conflict (Gerrand and Grossman), this article explores Farah's treatment of the dynamic trajectories of radicalization and resilience to violent extremism in the twenty-first century.

\section{Violent extremism in $\mathbf{2 I}^{\text {st }}$ century literature}

Violent extremism is a complex, increasingly networked, phenomenon. Radicalization to violence has been the subject of considerable sociological research (Cottee; Nilsson; Joosse et al.; Ranstorp; Thomas) and, to a lesser extent, the subject of cultural analysis focused on the subjects, objects and techniques of representation. Fiction is an ideal arena for challenging dominant assumptions about who turns to terrorism and why, and can get to the

Vivian Gerrand is a research fellow at the Alfred Deakin Institute for Citizenship and Globalization, Deakin University, Melbourne, Australia, and is the author of Possible Spaces of Somali Belonging (2016).

Email. vivian.gerrand@deakin.edu.au

(iD https://orcid.org/0000-0002-3169-547X

DOl: dx.doi.org/10.17159/2309-9070/tvl.v.57i1.8080

DATES: Submitted: 22 June 2019; Accepted: ISeptember 2019; Published: 28 April 2020 
heart of the motivations and environments that permit such trajectories of engagement with violence in a manner that is hard to pin down in sociological research.

In recent years, writers such as Mohsin Hamid and Kamila Shamsie have explored the nuances of the dynamics of terrorism in their respective works of fiction: The Reluctant Fundamentalist (2007) and Home Fire (2017). Published ten years apart, Hamid and Shamsie's novels both address jihadist terrorism but differ in their focus: The Reluctant Fundamentalist is set in the Al-Qaeda era, while Home Fire takes place in the context of the Daesh group's influences. Even more recently, author Hassan Ghedi Santur's 2019 novel, The Youth of God, takes as its subject matter the radicalization trajectory of a teenaged Somali-Canadian boy and explores the ways in which lack of belonging and Islam have been exploited for political gain by al-Shabaab. In different ways, each of these authors pushes readers to think globally while suggesting local, pro-social, potential mitigating contributing factors to radicalization processes.

Farah in North of Dawn is less concerned with any one brand of terrorism. Instead, the author successfully addresses the ways in which the contemporary actions and rhetoric of extremist groups feed each other's processes of what some scholars of terrorism have controversially called "reciprocal" radicalization (Knott; Lee and Copeland 5). Whether or not one agrees with this idea, Somali-Norwegian protagonist Mugdi's reflections on such processes are a leitmotif in the novel: "I would say that the violent culture of right-wing groups here in Europe is very much like Shabaab's," says Mugdi. "I am of the view that the two radical groups feed off each other" (North 180).

Farah is alert to the fact that violent extremism is not limited to any particular ideological or religious denomination. The author's decision to stage North of Dawn in Norway reflects this. On the one hand, the country was a victim of far-right lone actor Anders Breivik's terrorist attack in July 2011. On the other, an unusually high number of radicalized young Norwegians travelled to Syria and Iraq to join the so-called Islamic State, suggesting the extent to which right-wing xenophobia may contribute to Islamist radicalization (Fabricius).

Farah does not shy away from the role of Islamophobia in Western societies that has legitimated the narratives of incompatibility fostered by far right and Islamist extremist organizations. Indeed, far right and Islamist actors have taken explicit advantage of misunderstandings of Islam perpetuated in dominant media, strategically deploying images that are designed to heighten antagonism towards Muslims, in order to further marginalize Muslim minorities living in the West for political gain (Wignell et al. 17). Attention towards this strategy is a leitmotiv in the novel: "Silent, all three are aware of the battle lines that have been drawn between two minority groups: on one side, the neo-Nazis, with their anti-Islamic, anti-immigrant smear campaigns, and on the other, the jihadis, small in number when you think of the world's Muslim population of a billion plus. These two are at war and the rest are victims" (North 93). Both groups seek to escalate conflict between monolithic categories such as the West and Islam, and dismiss attempts to understand the complexities of dynamic historic relations between religion and society.

Farah challenges the apocalyptic aims of such extremists through exposition of their fascist hypocrisies, and the ways in which these are casually reinforced by "a cottage industry of populist politicians [...] who aim their propaganda at the least educated among their citizenry" (North 226). In North of Dawn, calculated attempts to polarize the world into black and white in order to destroy the gray zone of democracy (Arts House) are denounced and resisted. Farah sustains this resistance by privileging the gray contours of conviviality that emerge through the humanity of his complex characters. In the following sections, I analyze the novel's cast of characters considering, in particular, who radicalizes and who remains resilient to violent extremism.

\section{Trajectories of radicalization to violence}

At the outset of North of Dawn, the Somali background protagonist, Mugdi, and his wife, Gacalo, receive the news that their son, Dhaqaneh, has died in a suicide attack. After fleeing to Somalia, Dhaqaneh joined the al-Shabaab terrorist organization and was married to a local woman, Waliya. Having grown up with empathetic and supportive parents, in a well-resourced home full of "books in all sizes in every genre, in Italian, English, Russian, Somali, Arabic, and Norwegian" (53), Dhaqaneh's radicalization to terrorism may seem unusual. Farah's decision to have a middle-class character radicalize affirms the fact that people from all backgrounds can be vulnerable to recruitment, especially when they feel there is "no room for them in society" (Khosrokhavar 175). Indeed, a small minority of young people have found cultural belonging in taking on and being socialized into the ideologies of extremist groups such as the Islamic State Group (IS), whose sophisticated marketing includes social media apps 
to befriend and indoctrinate and specifically targets disenfranchised Muslim youth (Galloway; Grossman et al.). Studies of why people become involved in violent extremist organizations reveal that they most often join to be part of something, that is, for social rather than ideological reasons (Barelle, Grossman, et al.; Cottee; Nilsson). Recent research finds that a weak sense of national identity and civic belonging increases the vulnerability of first and second-generation immigrants to such mechanisms of socialization (Nilsson 350).

As Muslims with sub-Saharan African heritage, Somalis are visibly different from the dominant communities in which they have settled in the West. With a strong visual presence, identity development in the diaspora is complex and Somalis are commonly viewed as outsiders, leading them to be considered as among the most marginalized of Muslim migrant minorities and vulnerable to radicalizing influences. In addition to the struggles surrounding belonging in their host societies, Somali communities tend to be fragmented along clan lines. At the same time, as will become clear in the next section, Somalis are more often than not highly resilient, having dynamically pioneered new networks and possibilities for belonging in the twenty-first century (Gerrand, Possible Spaces of Somali Belonging 232).

The "signs" of Dhaqaneh's radicalization include behaviors such as social isolation. In the manner of many adolescents, Mugdi recalls that "when puberty took total command of his [son's] mind and body", he would spend "more and more time alone in his room, the curtains drawn, listening to loud music, surfing the internet, and watching porn" (North 16). It is significant that Dhaqaneh is described by his father as a "person of extremes" from a young age, who would "insist on eating nothing but spaghetti for weeks on end, only to announce that he wanted no more spaghetti for months" (18). This penchant for extremes resonates with the finding in a recent Australian study that interviewed the family members of young people who joined violent extremist conflict that black and white thinking is a common feature of people who radicalize to terrorism (Gerrand and Grossman 14-7). In comparison to his sister, Timiro, Dhaqaneh is the lower achiever of the two. Mugdi wonders whether his son was finding it difficult to live in the same house as her: "For she was dutiful and he was not; she was hardworking at school and he was not; she excelled in everything at which she tried her hand and he did not; she showed future promise, he did not. Dhaqaneh hated being compared to her and hated her guts too" (16). Of the view that it will help their son, Gacalo takes Dhaqaneh on a number of trips to Somalia. On return from one such trip, Dhaqaneh tells his father he wishes to "purify Islam' from Western influences" (18). Mugdi recollects: "One evening at dinner, when conversation touched on Al Qaeda's bombing of the US embassies in Nairobi and Dar es Salaam and the 9/11 massacre, Dhaqaneh declared that Islam was the one faith that would save the world and everyone on it from perdition and, if need be, he was prepared to kill to achieve this" (18). Moreover, Dhaqaneh considers "all non-Muslims [...] creatures bereft of souls" who are not "full humans". His zero-sum thinking is on display when he admits to his father that he "wouldn't hesitate to exterminate them" (20). Whilst in Somalia, Dhaqaneh was likely influenced by a shift to "a different Islam from the one [his family] were raised on" (61). This Islam is characterized by a new set of Salafi customs, foreign to the Sunni Islam with Sufi elements hitherto practised in Somalia, that become visible once Waliya arrives in Norway. Waiting for Waliya to answer their knock at the door of her apartment, Gacalo explains: "Whereas in former times, Somalis were relaxed about the genders mingling and spaces were not necessarily allotted to specific genders, our people have recently adopted the more conservative, stricter, Wahhabi tradition, which stipulates that different entrances are assigned to the two genders" (62).

This shift in attitudes is symptomatic of the devastating conditions produced by two decades of civil war, which have displaced approximately two million Somalis who now live in the diaspora. It has also damaged Somali heritage and culture. Isakhan argues that the destruction of cultural heritage by extremist groups such as the so-called Islamic State arguably plays a key role in violent extremism insofar as it erases the cultural memory of human groups' rich traditions, creating a vacuum which may be readily filled with propaganda (242). Somalis both within and outside of Somalia may be vulnerable, therefore, to groups and ideologies that fill this vacuum. Moreover, understanding Dhaqaneh's trajectory of radicalization to violence requires that we appreciate the European context he left, in which migration is routinely perceived as a threat, rather than a source of strength and opportunity. Dhaqaneh's family friend, Fredrik, sums up this predicament: "[H]ere in Norway, the Somalis are very much unwelcome, being black Muslim refugees at a time when migration is now viewed both as a political problem and as a threat to the Norwegians' continued existence as a "pure race" (183). Within such dominant discourses of national identity, the racialization of Somalis as "incompatible" results in the stigma of being "excluded [...] harassed" and "discounted as a person" (Fangen 7l-2). Unlike natives, the worst is expected of them. Following the Breivik far right terrorist attack, Mugdi's brother Kaluun muses on this double standard: when "a 
native European is responsible" for a terrorist attack, "every attempt is made to prove that he was suffering from some form of mental disorder or is emotionally impaired" (222). Muslim minorities, on the other hand, are already "suspect" (Hickman et al. 91) and are thus not given the benefit of being able to appeal to mental illness.

A lack of equal treatment or opportunity follows such discrimination, producing a dynamic of humiliation to which Somalis are subjected. Islamist groups such as al-Shabaab promote the offer of a new life of possibility, agency and dignity outside of Norway; their appeal to a minority of Somalis has its roots in this reality of discrimination and humiliation. Indeed, Dhaqaneh finds greater sense of purpose, legitimacy and belonging outside Europe, in his parents' homeland, Somalia. The extremist ideology into which Dhaqaneh is socialized provides a "set of justifications that legitimises an in-group, which is primarily expressed through texts, including both the written and spoken word" (Berger 7). According to Berger, a sense of legitimacy is thus frequently granted to otherwise disenfranchised people through extreme movements. The extreme ideologies underpinning such movements may be used selectively as "a tool [...] by violent extremists to construct their 'system of meaning' in response to psychosocial and strategic factors" (7). Dhaqaneh's perceived lack of legitimacy underpins his radicalization to terrorism which occurs when the pull of the opportunity of joining al-Shabaab combines with the push of discrimination. His radicalization trajectory recalls the reports of families interviewed for an Australian study that online violent extremist influences presented an "exciting picture of what [young family members] could do with their lives." These influences appeared to offer: "a much-needed sense of adventure, belonging, dignity and purpose through [...] redemptive narratives which served to instil in these vulnerable young people the idea that they can become heroes by joining a violent extremist movement" (Gerrand and Grossman 11).

In the aftermath of his suicide, Dhaqaneh's parents argue about whether to bring his wife and stepchildren, Naciiim and Saafi, whom they have never met, to Oslo. Mugdi is "at loggerheads" with Gacalo over whether they should allow their son's wife and her children to join them in Oslo by sponsoring them with a family reunion category visa. Mugdi worries about "what may become of [them] if Waliya turns out to be a troubled person, or, even worse, a terrorist" (4). Mugdi's fears are well-founded. Waliya is an easily-led opportunist who swings from promiscuity to austerity, often neglecting her children's needs. Taking her tea with "three sugars" (100), Waliya is hardly a model of piety: her chequered past is regularly alluded to, and her radicalization to Wahhabism appears to be an attempt to redeem herself from it. Her son, Naciim, in conversation with Gacalo, reflects that prior to meeting his stepfather Dhaqaneh: "Mum was always more into nightclubbing than praying and [...] seldom set foot in a mosque" (131). In replacing one set of extreme behaviors with another, her agency is often limited to what she can do for men. In Oslo, her authoritarian approach alienates her from her son, whom she reprimands for prioritizing his studies over the punctual performance of his five daily prayers. Naciim is prepared to say his prayers later in the day, acknowledging that "Islam allows that, but my mother doesn't $t$ " (131).

Waliya's trajectory is not unique. An Australian study that interviewed the family members of young people who joined violent extremist conflict found that some of these young people turned to devout practices in an effort to distance themselves from past substance abuse (Gerrand and Grossman 10). Waliya's history of trauma, inability to adapt to her host country and zero sum thinking make her vulnerable to terrorist recruitment. Such thinking is evident in her derision of her son's plan to participate in Norway's Constitution Day celebrations:

Naciim's eagerness for tomorrow's festivities is tempered by the fury he feels at his mother and the way she mocked him for preparing to join the Constitution Day celebrations. She practically forced him out of the house with taunts meant not only to wound his pride but also to question his very identity - for how could he now consider himself a Somali, or even a Muslim, his mother demanded. (154)

When Waliya finds some of the Norwegian flags Naciim has purchased to take with him, she destroys them on the grounds that she will have "no cross in [her] house" (154-5). Her black and white worldview that non-Muslims, and Muslims who do not strictly adhere to Salafism, are evil manifests in disrespect towards Naciim's friend, Edvart: "When [Naciim] recalls how rude his mother was to Edvart, chasing him out of the apartment as if he were a tramp, merely because his friend is not a Muslim, he decides that her attitude is no different from that of the neo-Nazis, those nativist skinheads so violently opposed to foreigners in their midst" (148).

After Waliya begins a new relationship with terror suspect, Zubair, this worldview sharpens into violence towards her own son. When Naciim returns home smelling of alcohol, after a friend spilled wine on him, Waliya instructs her "charlatan" friends, Cumar and Imam Fanax, to administer "fifty lashes". Sadistically delighted at the opportunity to "punish the boy", belt in hand, Fanax: "strike[s] him with as much force as possible [...] He wants 
everyone to know that the belt has made its mark, and the longer it takes for Naciim to issue a groaning sound of pain, the harder he will be hit" (234). With Gacalo and Mugdi's assistance, Naciim reports the attack to the police, before going to the hospital emergency unit where a nurse takes photos of his injuries "noting the discoloration on his back and the cuts that will require care for a month at least" (235). Akin to her friend Arla, whom Naciim observes to "cause havoc wherever she goes" (198): "Waliya is forever creating havoc, unable to come to terms with her new country's climate, culture or faith, nor able to tear herself loose from all that defined her back in the land where she was raised" (195). However, unlike Arla, who refers to herself as "a woman for all seasons", and switches between the dirac, traditional Somali guntiino and "the full Muslim outdoor gear", Waliya's religious convictions impair her flexibility. They do not even allow her children to listen to music and "she discourages them from watching TV because they may glimpse men or women in flimsy summer wear" (304).

Having rejected life in Norway, Waliya eventually departs Oslo to return to Mogadishu, where she ostensibly has a job in a hotel. She calls her children intermittently, but they are unable to reach her on her mobile number: "Naciim presses the redial a moment after she rings off, with the purpose of checking if his mother's number works. It doesn't. A week later, his mother telephones again, using a new number. When he asks her about these numbers, his mother is cagey, unprepared to tell him where she is, or why her numbers keep changing" (369). The novel ends with her son's reflection that his terrorist stepfather, Dhaqaneh, used to change his number often too.

The rise of far right and Islamist populist rhetoric has fortified 'either/or' thinking that risks encaging diasporic Somalis as illustrated by Dhaqaneh and Waliya's trajectories of radicalization to terrorism. The next section highlights what enables the resilience of characters who reject violence in spite of vulnerability in North of Dawn.

\section{Trajectories of resilience}

In the $21^{\text {st }}$ century, an age characterized by global connectivity, it is increasingly common to live in between cultures, and to uphold multiple affiliations. Moreover, this experience is no longer limited to people who have migrated from one place to another (Amin 13). And yet, in the face of uncertainty, the need to solidify and fix identity as being of a particular place and genealogy has assumed prominence in the turn of some towards nostalgic movements that reify exclusivist, racialized and nativist identities (Bauman 3; Glick Schiller 104). In light of this, akin to a number of European Somali-background authors, Farah's privileging of multiplicity challenges thinking that seeks to partition cultural groups through Manichean reasoning.

Studies that have sought to understand the resilience of Somali communities to violent extremism have been undertaken by Grossman and Tahiri and Grossman et al. in Melbourne, Australia, by Weine and Ahmed in Minnesota, the USA, and by Joosse et al. in Canada. Two recent studies have examined Somalis' vulnerability as well as resilience to violent extremism in the contexts of the United States and Australia: Weine and Ahmed's study "Building Resilience to Violent Extremism Among Somalis in Minneapolis-St Paul", and Grossman, Stephenson and Tahiri's "Harnessing Resilience Capital: An Investigation of Resilience and Cultural Diversity in Countering Violent Extremism", in Melbourne, Australia. These studies pioneered a framework for researching violent extremism in relation to community resilience. Weine and Ahmed devised a model, Diminishing Opportunities for Violent Extremism (DOVE), to identify protective resources that can help mitigate the risk factors for involvement in violent extremism (2). These studies found that having a positive cultural image and identity, including family and community support networks, and access to traditional knowledge, are key to being resistant to violent extremism. At the same time, Grossman et al. found that the emphasis on bonding within the Somali community in the form of loyalty to the collective family and community, when it overrides individual wellbeing, can produce expectations of conformity to traditional norms that may not, in fact, be desirable for young Somalis for whom bridging capital is as important in their diasporic contexts. Bridging capital was defined in this study as "the capacity to link and interact meaningfully between communities with different backgrounds, values and belief systems" (18) Grossman et al. found that when bonding capital is privileged at the expense of bridging capital, young people within their Somali communities may experience alienation or expulsion from their family groups, placing their cultural resilience at risk (18). Flexible, as well as complex, cultural identities are vital, then, in enabling young Somalis to experience healthy cultural identity and belonging-factors that prevent socialization into violent extremism - in their Western contexts. Such complex, flexible identities have become an everyday unremarkable reality in many parts of the world, and are on display in a growing number of literary works that consider the predicament of Somalis in the diaspora. 
Within the Italian context, for example, Igiaba Scego has modelled such bridging capital through a championing of complexity that is central to her activism, short stories and novels. Scego draws on her deep insight into what it means to be African and European and at home "where one is" (Carroli and Gerrand 8), to write characters who negotiate with varying degrees of success their Somali-ness in European and Somali contexts (Gerrand, Possible Spaces 153). Likewise, the novels of Cristina Ali Farah feature characters who are thoroughly of their European location - be it in London, Rome or Belgium - while maintaining their Somali heritage (Gerrand, "Representing Somali Resettlement" 292; "Mending Mogadishu" 24). Kaha Mohamed Aden is another Italian Somali writer who has imagined in between understandings that build bridges and thereby contribute to convivial co-existence. As in Nuruddin Farah's novels, identity in Aden's, Ali Farah's and Scego's works is dynamic and responsive. Such works might be considered in terms of an aesthetics of adaptation, as they feature characters who have found belonging beyond an either/or struggle which allows them to be both here and there on trajectories of resilience.

The characters through whose eyes North of Dawn is narrated, namely Mugdi and his step-grandson Naciim, are both highly resilient. Since Mugdi met Naciim at the airport, "he knew right away that they would get along" (303). Naciim displays resilience in his ready affiliation with Norway's customs, while maintaining his Somali identity (153-4). As noted in the previous section, Naciim dedicates himself to learning the local language and customs, forms friendships, and a relationship with a local non-Somali Norwegian, while maintaining loyalty to his heritage. Naciim's embodiment of cosmopolitan belonging and futurity in Norway impresses Mugdi:

It has always disturbed Mugdi that Somalis in Norway tend to attract bad press, and seem relegated to the lowest rung on the economic ladder, unable to see beyond their ideological and religious constraints, and so unable to ever really advance. As Mugdi steps aside for Gacalo to enter the Nielsens' home, he feels certain that Naciim and his generation of fresh-faced, ambitious young Somalis will change all that. (177)

Mugdi likewise lives a cosmopolitan existence, with friends of a variety of backgrounds. Working as a translator into Somali of his "favourite Norwegian novel", Ole Edvart Rølvaag's Giants in the Earth (1927) helps to take his mind off his son's fate and to put into perspective his migration to Norway by comparing it with the historic context of Norwegian migration to Minnesota (9). Following the death of his wife, Mugdi struggles with grief, but still manages to begin a new relationship with a non-Somali Norwegian woman, Nadia, a friend of mutual friends Birgitta and Johan who is "head of the special reference collections at the National Library, responsible for antique, rare, and irreplaceable books" (302). While connecting with Nadia does not lessen Mugdi's loss, it enables him to share life once more in the present with an empathetic companion who is also his intellectual equal. Nadia's presence in Mugdi's life also protects him from Arla's sinister late-night attempt to infiltrate his home after Gacalo's death (349).

Naciim's sister, Saafi, is significantly more traumatized when she arrives in Oslo, having been gang raped in the refugee camp where she was living. Nonetheless, Saafi too proves to be remarkably resilient, supported as she is by Gacalo and Mugdi and their daughter, Timiro, when she visits Oslo from Geneva. For Saafi's mother, Waliya, the only cure to her daughter's PTSD would be "from reading the Koran" (60). Behind Waliya's back, Gacalo takes Saafi to see a Somali psychologist, Qumman, who is a friend of Timiro's. Qumman succeeds in helping Saafi's "memories scare [her] less than before" (96) and in regaining "her sense of self" (191). After Gacalo takes her stepgrand-daughter shopping, Naciim tells Gacalo that he has observed Saafi putting on "one of the four dresses you bought for her and spend[ing] several hours each day in front of the standing mirror in Mum's room, admiring herself" (121). If we think of changing clothes as a metaphor for identity as a dynamic process, Saafi embarks on a healing trajectory that gives her the courage try on different ways of dressing, and of being herself in the world. This trajectory of resilience is enabled by the preservation of her Somali cultural identity and her adaptation to Norwegian society.

Saafi's newfound interest in clothing contrasts with her mother's dress code. Farah challenges stereotypes about piety of women in niqabs through the female Somali characters such as Arla and Waliya. The author highlights the vacuity of equating piety with any particular garb, the paying of "lip service to the faith" while living "a life of lies" (350) and privileges instead the piety of character demonstrated by Mugdi and Gacalo. Farah is not critical of religion per se, but rather of the ways in which people distort and exploit religion for self-serving ends (Pucherova 33). The example of Somali Muslims drinking alcohol in social situations is an important case in point in North of Dawn. Mugdi and Gacalo do not adhere to traditional Muslim codes such as abstaining from alcohol, nor do they misuse alcohol. Their occasional social drinking is appropriate to their social context. At Gacalo's 
funeral, alcohol is served in mugs, for example, catering at once for those who drink while expressing sensitivity towards those who abstain (266). In this sense, Farah's depiction of Islam resonates with the critique of critical Muslim Studies scholars who contest essentialist understandings of the religion by attempting to move beyond Arab-centric interpretations of the consumption of alcohol (186). The scholars in question take into account a variety of Islamic contexts in which it is intoxication, rather than alcohol itself, that is prohibited (Sheikh and Islam 187). In this sense, the author upholds the view that there are as many ways to practise Islam as there are Muslims (Sweid 29).

This view departs significantly from the religious perspective adopted by characters such as Waliya to whom a strict literal Wahhabist interpretation, and reification, of Islam appeals. Indeed, reified identities do appeal precisely because they appear to promise security to vulnerable, uncertain and insecure people living at the margins of societies in a globalized world. These people may be recent migrants like Waliya, but in Europe they are more often nativist white supremacists like Breivik, whose terrorist attack is responsible for killing one of North of Dawn's most resilient and hopeful Somali Norwegian characters, Mouna:

Anders Behring Breivik, a native Norwegian, after a lengthy planning process, first detonated a bomb close to the Norwegian premier's office in the centre of Oslo, in which eight people lost their lives, before heading to the wooded island of Utoya, where young acolytes of the country's governing Labor party were attending youth camp, and proceeded to mow down sixty-nine more, most of them teenagers. One of the dead was Mouna: charming, exuberant, barely eighteen, soccer-playing Mouna, Himmo's daughter, loved deeply by all who knew her, especially Naciim. (209)

Mouna's mother, Himmo, "a woman of dignity" (211), is another beacon of resilience in North of Dawn. For Mugdi: "the key to understanding Himmo, as a woman and a human being, is in understanding her marked commitment to her children's well-being, her absolute devotion to her career, and her insistence that her future depends on her own hard work and her efforts as a Somali-Norwegian." In contrast to Waliya, Himmo takes responsibility for her children and for her career and, significantly, "can no longer think of herself as Somali without also thinking that she is Norwegian" (212). The bridging capital she cultivates represents a departure from the straightjacketed mentality of Waliya, who refuses to learn the local language and discourages her children from joining Norwegian society out of fear this will annihilate their Muslim and Somali identities, Himmo raises her daughter "to embrace her hyphenated identity" (212). Mugdi reflects on his relationship with Himmo:

Many memories revisit Mugdi: Himmo as a young girl asking him to lend her books to read; Himmo as a basketball player in Mogadishu, leading her team from the front and scoring points; Himmo visiting them in Bonn on a few months' refresher course, staying up late practicing her German to ensure that she mastered the language in the shortest time possible; Himmo announcing the collapse of her first marriage, and then her second, both times working hard to pull herself together and succeeding. No matter the challenge, she has always survived, and she produced three wonderful children. The tragedy is that one of them is now dead at the hands of Breivik. (225)

Farah privileges the capacity to negotiate multiple affiliations of characters who are at once cosmopolitan, and yet very much rooted in their European national realities. Unlike the "cosmopolitan cast" of the author's 2014 novel Hiding in Plain Sight, in which not one character is "born, works, marries and dies within a fixed locale" (Moolla 69), North of Dawn's characters could hardly be described as "post-national". The 2018 novel's protagonists' ties to their adopted or abandoned countries are consistently upheld, even in the face of recent migration. As we have seen, identity for Waliya is an either/or proposition: she rejects Norway in favor of her homeland, Somalia, while her children embrace their new country, developing bridging capital by learning the language and coming to identify with being both Norwegian and Somali.

In this way, Farah echoes critical understandings of identity as a product of both routes and roots, and therefore regards both alienation and assimilation as dead ends insofar as neither response accommodates the realities of belonging in the twenty-first century. Gacalo and Mugdi's Somali-Norwegian friend, Suudi, who has completely rejected his heritage is an example of the undesirability of assimilation. Suudi lives with his Norwegian partner, Ingrid, and tells the tale of their dog "shar[ing] their bed at night and eat[ing] its food off their plates." (265) Kaluun thinks there is "nothing wrong in [his friend] stressing how he has struck out on his own, but what good has Suudi done for other Somalis, culturally, politically, or in any other way? None" (266). Mugdi, Gacalo, Timiro, Naciim, Saafi, Himmo and Mouna on the other hand enact a third way of developing bridging capital, that comprises multiplicity, complicating singular affiliation. In conversation with an academic family friend, Fredrik, 
who is working on a comparative analysis of the first Norwegians to settle in Minnesota and the more recently arrived Somalis, Frederik tells Gacalo and Mugdi he is “coming around to the idea that you can't do well in a new country if you don't have a good measure of the one you left behind" (183).

A 2017 Australian-Canadian study that pioneered a measure for understanding youth resilience to violent extremism affirms that living identity as a dynamic process, with an ability to maintain social networks across multiple affiliations, or bridging capital, is a key factor in what makes young people resilient to violent extremism (Grossman et al. 13). A principle danger to resilience to violence, therefore, is the brittleness, embodied in North of Dawn most emphatically by Dhaqaneh and Waliya, that comes from needing to define oneself as one or another thing, without ambiguity. It is well-recognized that violent extremist groups exploit such fragility; it is what allows their offers of uncomplicated belonging to go unquestioned in their recruitment of a minority of people.

Farah's North of Dawn privileges the lives of characters who successfully inhabit their Somali and Norwegian affiliations, and in so doing, subvert reified identities. At the same time, as might be expected, Farah critiques the paths taken by characters who refuse to adapt, and instead seek refuge in extremist ideologies that take them towards violent action. These characters are as destructive when they gravitate towards the ideologies of the far right, as they are when joining Somalia's al-Shabaab movement. In the face of this, Farah's protagonists Mugdi, Gacalo, Timiro, Naciim, Saafi, Himmo and Mouna display a range of strategies for belonging and identification in Norway that enable them to retain fluency across their multiple cultural affiliations, affording them resilience.

Dialectical thinking about identity is thus critical to understanding the logic of Farah's characters' trajectories. As we have seen, those incapable of it are given short shrift. Mugdi's son, Dhaqaneh, removes himself from his Norwegian upbringing, rebelling against it to become a fighter for a terrorist organization that promises him renewed dignity. A suicide bomber who has rejected his upbringing in the West and embraced the black and white jihadist ideology, Dhaqaneh dies before the timeline of the narrative begins. His wife Waliya fares little better. And his stepchildren thrive when they begin to adapt to their new country, all the while maintaining their Somali cultural heritage. The characters Farah most valorizes display an aesthetics of adaptation, having found belonging beyond an either/or struggle which allows them to be both here and there on trajectories of resilience.

\section{Works Cited}

Aden, Kaha Mohamed. Fra-Intendimenti. Nottetempo, 2010.

Amin, Ash. Land of Strangers. Polity, 2012.

Arts House. "The Believers Are But Brothers: Javaad Alipoor \& Kirsty Housley [Performance]."Arts House, www.artshouse. com.au/events/the-believers-are-but-brothers/. Attended 24 May 2019.

Barelle, Kate. "Pro-integration: disengagement from and life after extremism." Behavioural Sciences of Terrorism and Political Aggression vol. 7, no. 2, 2014, pp. 129-42. DOI: https://doi.org/10.1080/19434472.2014.988165.

Bauman, Zygmunt. Retrotopia. Wiley, 2017.

Berger, John M. "Extremist Construction of Identity: How Escalating Demands for Legitimacy Shape and Define In-Group and Out-Group Dynamics." International Centre for Counter Terrorism-The Hague no. 7, 2017, pp.1-68. DOI: https://doi. org/10.19165/2017.1.07.

Carroli, Piera, and Vivian Gerrand. "La mia casa è dove sono: Subjects and narratives beyond national borders." Scritture migranti, no. 5, 2011, pp. 81-104.

Cottee, Simon. "Jihadism as a subcultural response to social strain: Extending Marc Sageman's 'Bunch of Guys' Thesis." Terrorism and Political Violence vol. 23, no. 5, 2011, pp. 730-51. DOI: https://doi.org/10.1080/09546553.2011.611840.

Fabricius, Peter. "Op-Ed: Fighting Extremism while keeping democracy alive." Daily Maverick. 13 Nov. 2016. www. dailymaverick. co.za/article/2016-11-13-op-ed-fighting-extremism-while-keeping-democracy-alive/. Accessed 3 Jun. 2019

Fangen, Katrine. "Humiliation Experienced by Somali Refugees in Norway." Journal of Refugee Studies vol. 19, no. 1, 2006, pp. 69-93. DOI: https://doi.org/10.1093/jrs/fej001.

Farah, Nuruddin. North of Dawn. Riverhead, 2018.

Galloway, Chris. "Media jihad: What PR can learn in Islamic State's public relations masterclass." Public Relations Review vol. 42, no. 4, 2016, pp. 582-90. DOI: https://doi.org/10.1016/j.pubrev.2016.03.014.

Gerrand, Vivian. "Mending Mogadishu. Somali Belonging in the twenty-first century." Arena Magazine, Dec. 2015-Jan. 2016, pp. $22-5$. Possible Spaces of Somali Belonging. Melbourne U P, 2016.

. "Representing Somali Resettlement in Italy: The Writing of Ubax Cristina Ali Farah and Igiaba Scego." Italian Studies in Southern Africa vol. 21, nos. 1-2, 2008, pp. 270-95. DOI: https://doi.org/10.4314/issa.v2lil-2.43970.

Gerrand, Vivian \& Michele Grossman. Interviewing the Families of Young People who have Joined or Attempted to Join Violent Conflict [Report]. Alfred Deakin Institute for Citizenship and Globalization, Deakin U, 2017.

Glick Schiller, Nina. "Diasporic Cosmopolitanism: Migrants, Sociabilities and City Making." Whose Cosmopolitanism? Critical Perspectives, Rationalities and Discontents, edited by Nina Glick Schiller and Andrew Irving, Berghahn, 2015, pp. 103-20.

Grossman, Michele \& Hussein Tahiri. Harnessing Resilience Capital: An Investigation of Resilience And Cultural Diversity in Countering Violent Extremism. Victoria U P, 2013. 
Grossman, Michele et al. Understanding Youth Resilience to Violent Extremism: A Standardised Research Measure: Final Research Report. Alfred Deakin Institute for Citizenship and Globalization, Deakin U, 2017.

Hickman, Mary J. et al. "Social cohesion and the notion of 'suspect communities': a study of the experiences and impacts of being 'suspect' for Irish communities and Muslim communities in Britain." Critical Studies on Terrorism vol. 5, no. 1, 2012, pp. 89-106. DOI: https://doi.org/10.1080/17539153.2012.659915.

Isakhan, Benjamin. Heritage Destruction and Spikes in Violence: The Case of Iraq. Brill, 2013.

Joosse, Paul et al. "Narratives and Counter-narratives: Somali-Canadians on Recruitment as Foreign Fighters to Al-Shabaab." British Journal of Criminology vol. 55, no. 8, 2015, pp. 811-32. DOI: https://doi.org/10.1093/bjc/azul03.

Knott, Kim, Ben Lee \& Simon Copeland. Reciprocal Radicalization [Report]. CREST, 2018

Khosrokhavar, Farhad. Suicide Bombers: Allah's New Martyrs. Pluto, 2005.

Moolla, F. Fiona. "Postnational Paradoxes: Nuruddin Farah's Recent Novels and Two Life Narratives in Counterpoint." Research in African Literatures vol. 49, no. 1, 2018, pp. 68-83. DOI: https://doi.org/10.2979/reseafrilite.49.1.05.

Nilsson, Marco. "Foreign Fighters and the Radicalization of Local Jihad: Interview Evidence from Swedish Jihadists." Studies in Conflict and Terrorism vol. 38, no. 5, 2015, pp. 343-58. DOI: https://doi.org/10.1080/1057610x.2015.1005459.

Pucherova, Dobrota. "Islam, Tradition and Modernity in the Work of Two Somali Writers: Nuruddin Farah and Ayaan Hirsi Ali." English Studies in Africa vol. 59, no. 2, 2016, pp. 27-40. DOI: https://doi.org/10.1080/00138398.2016.1239416.

Ranstorp, Magnus, ed. Understanding Violent Radicalization. Terrorist and Jihadist Movements in Europe.

Sheikh, Mustapha \& Tajul Islam. "Islam, Alcohol, and Identity: Towards a Critical Muslim Studies Approach." ReOrient vol. 3 , no. 2, 2018, pp. 185-211. DOI: https://doi.org/10.13169/reorient.3.2.0185.

Sweid, Reem. "Tony Abbott Reinforces White Supremacists." Illawara Mercury. 10 Dec. 2015, www.illawarramercury.com.au/ story/3551875/tony-abbott-reinforces-white-supremacists/. Accessed 3 Sep. 2019.

Tellander, Ebba \& Cynthia Horst. "A Foreign Policy Actor of Importance? The Role of the Somali Diaspora in Shaping Norwegian Policy towards Somalia." Foreign Policy Analysis vol. 15, no, 1, 2019, pp. 136-54. DOI: https://doi.org/10.1093/fpal orx012.

Thomas, Paul. Responding to the Threat of Violent Extremism: Failing to Prevent. Bloomsbury, 2012.

Weine, Steven \& Osman Ahmed. Building Resilience to Violent Extremism among Somali-Americans in Minneapolis-St. Paul: Final Report to Human Factors/Behavioral Sciences Devision, Science and Technology Directorate. U. S. Department of Homeland Security, 2012.

Wignell, Peter, et al. "Violent extremism and iconisation: commanding good and forbidding evil?" Critical Discourse Studies vol. 14, no. 1, 2017, pp. 10-22. DOI: https://doi.org/10.1080/17405904.2016.1250652. 